\title{
Thermal Hydraulic Simulation of a Channel with Targets for Production of Selenium-75 Isotope
}

\author{
D. N. Litvinov ${ }^{1, \text { a) }}$, V. S. Kostarev 1 , b) O. L. Tashlykov ${ }^{1, c)}$, V. A. Klimova ${ }^{1, d)}$, \\ N. M. Aristov ${ }^{1, \text { e) }}$ and S. B. Zlokazov ${ }^{2, \text { f) }}$ \\ ${ }^{I}$ Department of Nuclear Power Plants and Renewable Energy Sources, Ural Federal University \\ named after the first President of Russia B.N.Yeltsin, 620002, 19 Mira street, Ekaterinburg, Russia \\ ${ }^{2} J S C$ "Institute of Nuclear Materials", Zarechny, Russia \\ a)Corresponding author: danil.litvinov@urfu.me \\ b)slavakostarev@yandex.ru \\ c)otashlykov@list.ru \\ d)v.a.klimova@urfu.ru \\ e)nikolay.aristov.95@mail.ru \\ f)sbzlokazov@gmail.com
}

\begin{abstract}
It is emphasized the importance of using radioisotope products in industry, science and medicine. Information is given on the generation of isotope products in the IVV-2M research reactor of Research Institute of Nuclear Materials, and the plans for expanding the range of radioisotopes produced. The features of the selenium-75 isotope production are described. The necessity of thermohydraulic simulation of the target for producing selenium-75 in the conditions of the IVV-2M reactor is substantiated. The process of constructing a solid-state model of the target and simulating the thermal conditions for the production of isotopes is described. In this work, the analysis of thermohydraulic processes was performed with Solidworks Flow Simulation software.
\end{abstract}

\section{INTRODUCTION}

Since the discovery of radioactivity, scientists have learned how to obtain radioisotopes with predefined properties that are used in various fields of science and technology such as medicine, biology, fault detection, etc. [1]. The role of radioisotopes is constantly increasing with the development of technological progress. They are obtained in nuclear reactors and particle accelerators. In the reactor production method, the target capsule is placed in the reactor core, where necessary isotopes are produced under the influence of neutron radiation [2,3]. Radioactive isotopes are transported to the consumer in special containers, the radiation protection of which depends on the type of radiation and its energy [4-6].

Thermal neutron medium-flow research reactor IVV-2M of the Research Institute of Nuclear Materials (Zarechny) was used in the 1960-1980s for research work in the field of radiation materials science, for testing of fuel compositions and the elements of reactor cores and other tasks. In the 1990s, INM JSC began production of radioisotopes. Today it successfully combines research work and production of radioisotopes. Now the production of radioactive isotopes employs more than $2 / 3$ of IVV-2M resources.

As a result of the analysis of alternative ways of the IVV-2M reactor use, a new area of activity was formed related to the development of technologies for the production of radioactive isotopes for applied tasks and scientific studies, as well as the production and commercial supply of radioisotopes for fault detection, nuclear medicine and pharmaceutical research. At present, INM JSC supplies the world market with Ir-192, C-14, Cs-131, Lu-177 and continues to improve the existing technologies and to develop the new ones [7].

The VII International Young Researchers' Conference - Physics, Technology, Innovations (PTI-2020)

AIP Conf. Proc. 2313, 070011-1-070011-6; https://doi.org/10.1063/5.0032212

Published by AIP Publishing. 978-0-7354-4053-1/\$30.00 
In the short and medium term, it is planned to organize new production facilities for the generation of isotope products I-125, Se-75, Ni-63, Y-90, etc. at IVV-2M reactor [8].

Selenium-75, being one of the most demanded radioisotopes, is used as a source of gamma radiation for fault detection and in medicine. This radioisotope is produced by neutron irradiation of natural isotope selenium- 74 . Selenium-75 is an alternative to iridium-192, it has longer half-life and provides softer spectrum of gamma radiation thereby increasing the sensitivity of radiographic control. Selenium-75 decays as a result of electron capture with a half-life of 120 days. The energy of the main emission lines is 121, 136, 265, 280 and $400 \mathrm{keV}$, and the average energy is about $215 \mathrm{keV}$ [9].

Irradiation devices for isotope production are a special element of a nuclear reactor. They are placed in the cavity of the fuel assembly and include cells from primary raw materials in which the desired isotope is formed under the influence of neutron irradiation.

Selenium- 75 melts at a temperature of $217^{\circ} \mathrm{C}$. It has a boiling point of $680{ }^{\circ} \mathrm{C}$. Its ability to react with many metals complicates the technology of its production. So, for example, if a selenium ampoule is made of titanium, at a temperature of $400{ }^{\circ} \mathrm{C}$, selenium interacts with the metal of the ampoule with the formation of through fistulas [10].

The structural features of the reactor and the nuclear-physical processes occurring in it cause difficulties in experimental study of heat transfer and hydrodynamics in the irradiation device for the production of the radioisotopes. That is why computer simulation method was selected to perform the analysis of the conditions of selenium-75 production. Modern software for the analysis of hydrodynamics and heat exchange are intended to solve various problems including the analysis of heat exchange in the models with complex structure. The capabilities of SolidWorks software and its additional module Flow Simulation were verified with by the example of several elementary problems from different areas of heat transfer and hydrodynamics. The simulation results were compared with the experiment and the results of highly specialized calculation codes. The Nuclear Power Plants and Renewable Energy Sources department of UrFU have been applying computer simulation for several years to improve the understanding the processes in the equipment of nuclear power plants and facilities [11-14].

\section{METHODS OF RESEARCH}

In this paper, we consider the simulation of thermohydraulic conditions for the production of the selenium-75 isotope in the IVV-2M reactor of the Research Institute of Nuclear Materials, JSC, located in Zarechny town.

For analysis, a core section consisting of 6 fuel assemblies, a rack with seven irradiation devices, seven shanks, and a base plate was selected. Each device contains ten aluminum tubes in which there are vanadium capsules with raw materials for producing the isotope. A model of the irradiation device shown in Fig. 1 was built, a simulation of the flow of coolant through the irradiation device in isothermal conditions was carried out $[15,16]$. The results obtained are consistent with the theoretical prediction of the flow through the model with a sufficient degree of accuracy. The layout of the area investigated is shown in the Fig. 2.

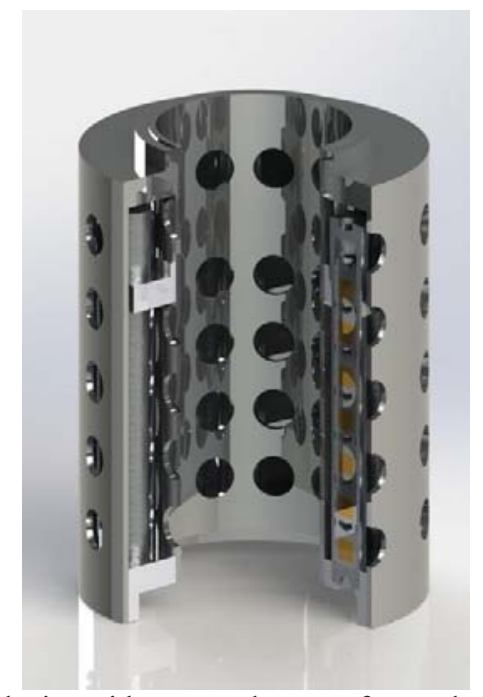

FIGURE 1. An irradiating device with mounted targets for producing the selenium-75 isotope 
The main structural material used in the model is aluminum. It is corrosion resistant to water, its decay products formed under the influence of radiation are short-lived, and it has a low thermal neutron capture cross section. Aluminum is also the main structural material of the IVV-2M core. Capsules are made of vanadium, since it is less susceptible to activation by neutron irradiation.

For the calculation of thermohydraulic processes, SolidWorks Flow Simulation software was chosen. Multiple studies show that computation with the SolidWorks Flow Simulation software gives the closest to the calculated temperature values. The results of other programs differ from the engineering calculation to a greater extent, which leads to the need for additional corrections, but does not make them less popular in engineering analysis of thermophysical processes [17].

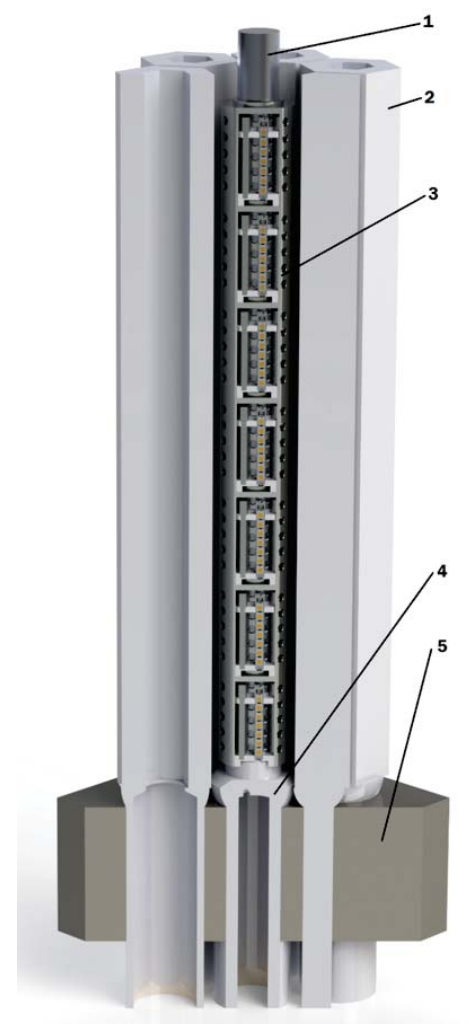

FIGURE 2. Render of the considered the IVV-2M reactor section of with a rack of strung targets for selenium production,

1 - rack; 2 - fuel assemblies; 3 - target; 4 - shank; 5 - base plate

The analysis of thermohydraulic processes in SolidWorks Flow Simulation is carried out on the basis of the NavierStokes system of equations for laminar and turbulent flows, which are the formulations of the laws of conservation of mass, momentum and energy for a liquid or gas flow [18]:

$$
\begin{gathered}
\frac{\partial p}{\partial t}+\frac{\partial}{\partial t}\left(p u_{i}\right)=0 \\
\frac{\partial p u_{i}}{\partial t}+\frac{\partial}{\partial x_{i}}\left(p u_{i} u_{j}\right)+\frac{\partial p}{\partial x_{i}}=\frac{\partial}{\partial x_{j}}\left(\tau_{i j}+\tau_{i j}^{R}\right)+S_{i}, \quad i=1,2,3 \\
\frac{\partial p H}{\partial t}+\frac{\partial p u_{i} H}{\partial x_{i}}=\frac{\partial}{\partial x_{i}}\left(u_{j}\left(\tau_{i j}+\tau_{i j}^{R}\right)+q_{i}\right)+\frac{\partial p}{\partial t}-\tau_{i j}^{R} \frac{\partial u_{i}}{\partial x_{j}}+\rho \varepsilon+S_{i} u_{i}+Q_{H},
\end{gathered}
$$

where $u$ is the fluid velocity, $\rho$ is the fluid density, $\mathrm{Si}=-\rho g i$ is a mass-distributed external force per unit mass due to a buoyancy, where gi is the gravitational acceleration component along the $\mathrm{i}$-th coordinate direction, $\mathrm{H}=\mathrm{h}+\mathrm{u} 2 / 2$, 
$\mathrm{h}$ is the thermal enthalpy, $\mathrm{QH}$ is a heat source or sink per unit volume, $\tau$ ik is the viscous shear stress tensor, qi is the diffusive heat flux. The subscripts indicate summation over the three coordinate directions.

The system of equations is closed with the state equations of the fluid and the empirical dependencies of the viscosity and heat conductivity on the temperature. To solve the turbulent flows, the RANS (Reynolds-Averaged Navier-Stokes) method is used. The additional equations for the Reynolds shear stress appear in the equations system:

$$
\tau_{i j}^{R}=\mu_{t}\left(\frac{\partial u_{i}}{\partial x_{j}}+\frac{\partial u_{j}}{\partial x_{i}}-\frac{2}{3} \frac{\partial u_{l}}{\partial x_{l}} \delta_{i j}\right)-\frac{2}{3} \rho k \delta_{i j},
$$

where $\delta \mathrm{ij}=1$ if $\mathrm{i}=\mathrm{j}, \delta \mathrm{ij}=0$ if $\mathrm{i} \neq \mathrm{j}-\mathrm{is} \mathrm{Kroneker}$ 's delta, $\mu \mathrm{t}-$ viscosity coefficient of turbulent vortices, $\mathrm{k}-$ kinetic energy of turbulence. To calculate laminar and turbulent flows, the same system of equations is used, but for a laminar flow $\mathrm{k}$ and $\mu \mathrm{t}$ are equal to zero. Within the framework of the $\mathrm{k}-\varepsilon$ turbulence model, where $\varepsilon$ is the rate of viscous dissipation of turbulence energy,

$$
\mu_{t}=f_{\mu} \frac{C_{\mu} \rho k^{2}}{e}
$$

$\mathrm{f} \mu$ - turbulent viscosity complex.

For the calculation, the flow conditions at the inlet and outlet of the simulated section were set. At the inlet, a boundary condition was created in the form of a volumetric flow rate of $12 \mathrm{~m} 3 / \mathrm{h}$, which corresponds to the actual flow rate through the reactor core section. At the exit of the model, the static pressure of the liquid was set. We used a highprecision calculation code using the Monte Carlo method to determine the specific heat in cells of selenium and vanadium capsules caused by gamma radiation and thermal neutrons, which are $4.5 \mathrm{~W} / \mathrm{gm}$ and $5.25 \mathrm{~W} / \mathrm{gm}$, respectively. A volumetric heat release value of $400 \mathrm{~kW}$ was set for fuel assemblies which corresponds to the energy release in the reactor. Since the model presents only a part of the reactor core, a symmetry condition was specified at the lateral boundaries of the computational domain.

The characteristics of materials in the form of a dependency of heat capacity, thermal conductivity and density on temperature were added to the model.

During the study, special attention was paid to the fact that the temperature of the cells for selenium production should not exceed the melting point of selenium, which is $217^{\circ} \mathrm{C}$. The temperature difference of the coolant along the length of the channel should be $25-35^{\circ} \mathrm{C}$ (Fig. 3-4).

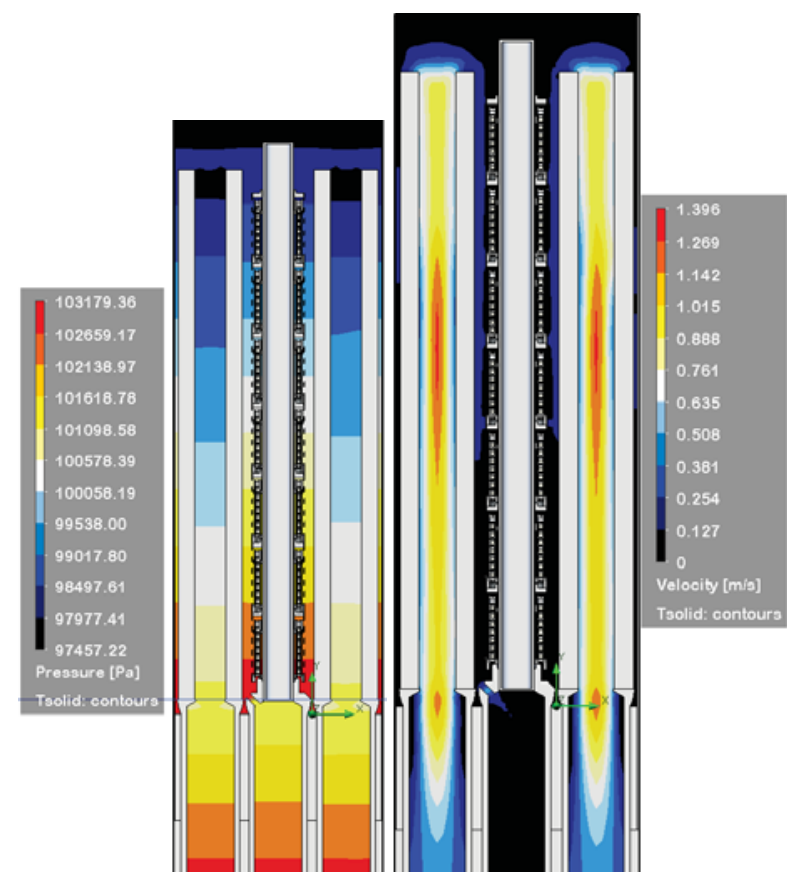

FIGURE 3. Simulation results 


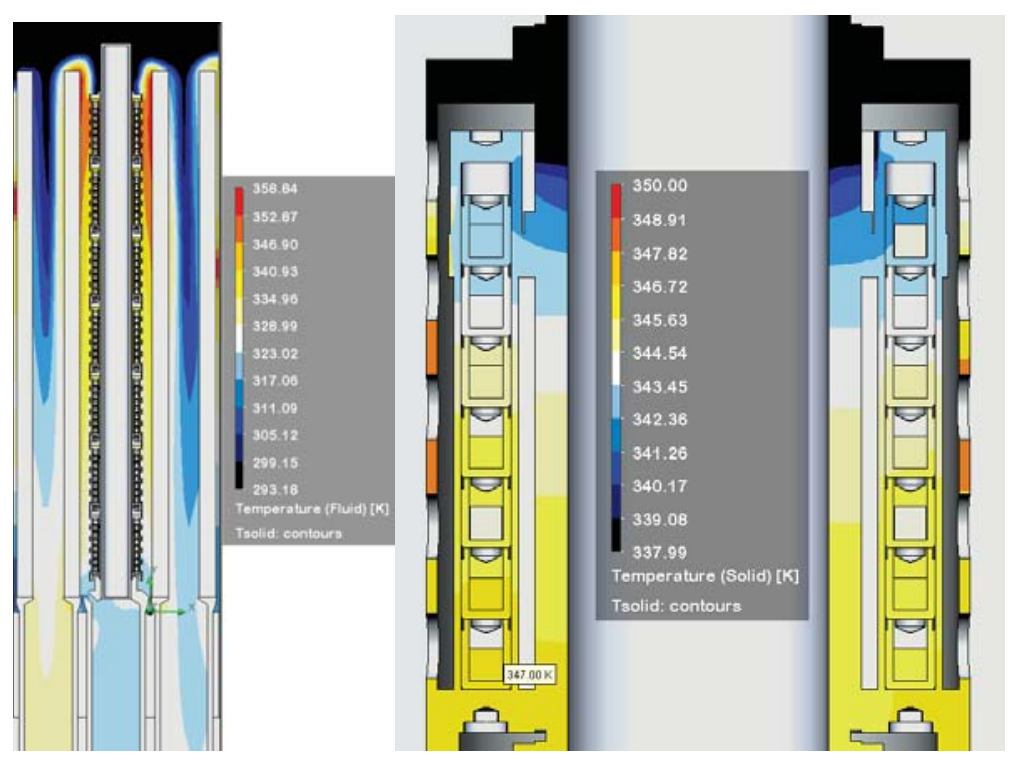

FIGURE 4. Simulation results

The temperature difference at the inlet and outlet of the core was 30.08 degrees with a volumetric flow rate of the coolant through the core section of $12 \mathrm{~m} 3 / \mathrm{h}$.

It was revealed in the process of calculation that the highest temperature $\left(74^{\circ} \mathrm{C}\right)$ is achieved in the first irradiation device in the direction of flow. This is connected with the high heat flow from the fuel assemblies and lower heat transfer rate at the inlet. The critical temperature was not reached due to the use of aluminum, a metal with high thermal conductivity.

\section{CONCLUSION}

On the base of simulation results it was made an analysis of the thermohydraulic conditions which appear under the influence of the thermal neutron flux during the production of the selenium-75 isotope in the active zone of the IVV-2M reactor.

The maximum temperature of a selenium cell is $74{ }^{\circ} \mathrm{C}$, with a temperature difference of $30.08{ }^{\circ} \mathrm{C}$. The plots of temperature distribution in materials and coolant, velocity and pressure fields are obtained. The use of aluminum with a high coefficient of thermal conductivity allows us to obtain acceptable values of the coefficient of heat transfer between the coolant and the walls of the tubes of the irradiation device separator, which guarantees the absence of overheating of the cells and reaching the melting temperature of selenium.

To verify the results of computer simulation of thermohydraulic processes during the production of selenium-75, it is planned to conduct experimental studies at the IVV-2M research reactor.

\section{REFERENCES}

1. O. L. Tashlykov, Fundamentals of nuclear power (Yekaterinburg, Ural Publishing house, 2016).

2. I. M. Russkikh, «Obtaining radioactive isotopes in a research nuclear reactor for experimental studies of the properties of homogeneous radiation-protective materials» in Proceedings of the 1st scientific and technical conference of young scientists of the Ural Power Engineering Institute (UrFU named after the first President of Russia B.N. Yeltsin, Yekaterinburg, 2016), pp. 254-257.

3. I. M. Russkikh, Physics of Atomic Nuclei 12(78), 1451-1456 (2015).

4. E. N. Seleznev, «Use of alternative radiation-protective materials in the transport of radioactive materials (for example, the source of lutetium-177)» in Proceedings of the 1st scientific and technical conference of young scientists of the Ural Power Engineering Institute (UrFU named after the first President of Russia B.N. Yeltsin, Yekaterinburg, 2016), pp. 274-277.

5. V. Yu. Litovchenko, AIP Conference Proceedings 2174, 1-8 (2019). 
6. V. Yu. Litovchenko et al., Voprosy atomnoj nauki i tekhniki. Materialovedenie i novye materialy 5 (101), 4-12 (2019).

7. S. B. Zlokazov et al., Atomic energy 4 (121), 227-233 (2016).

8. I. M. Russkikh, Atomic energy 4 (121), 183-187 (2016).

9. D. M. Chizhikov and V. P. Schastlivy, Selenium and selenides (Moscow, Nauka, 1964).

10. M. G. Shilton and Aston Clinton, EU Patent No. 00920911.5 (2000).

11. A. V. Kurteev, V. A. Klimova, M. M. Sevastyanov, and O. L. Tashlykov, AIP Conference Proceedings 2174, $020170(2019)$

12. V. S. Kostarev, V. A. Klimova, and O. L. Tashlykov, AIP Conference Proceedings 2015, 020044 (2018).

13. D. N. Litvinov, «Simulation of thermohydraulic processes in the storage mine of irradiated fuel assemblies of the IVV-2M reactor» in Proceedings of Scientific and practical conference Nuclear technologies: from research to implementation (NSTU, Nizhny Novgorod, 2018), pp. 18-19.

14. D. E. Shumkov, «Simulation of thermohydraulic processes in a coil heat exchanger to determine the efficiency of heat transfer» in Energy and resource saving. Energy supply. Non-traditional and renewable energy sources. Nuclear power engineering: materials of the International scientific and practical conference of students, postgraduates and young scientists (UrFU, Yekaterinburg, 2017), pp. 990-993.

15. V. S. Kostarev, «Thermohydraulic simulation of irradiation devices for working out isotopes» in Energy and resource saving. Energy supply. Non-traditional and renewable energy sources. Nuclear power engineering: materials of the International scientific and practical conference of students, postgraduates and young scientists (UrFU, Yekaterinburg, 2019), pp. 741-744.

16. I. A. Serkov, «Construction of a solid-state model of an irradiation device for the development of the selenium75 isotope» in Energy and resource saving. Energy supply. Non-traditional and renewable energy sources. Nuclear power engineering: materials of the International scientific and practical conference of students, postgraduates and young scientists (UrFU, Yekaterinburg, 2019), pp. 765-768.

17. V. N. Chernykh, Heat Engineering and Informatics in education, science and production 5, 266-270 (2017).

18. Technical Reference. Solidworks Flow Simulation 2020. 